\title{
Veneer, Plywood, and Wood Products
}

Wood has been used by the human race for millennia. And, although this product of the forests was used before civilization began, it continues to be a versatile material with widespread engineering applications.

In Egyptian times, and later in the Roman empire, craftspeople began sawing thin slices of wood from logs. The process, an arduous one, involved sawing lengthwise down the logs. Applying the resulting thin slices of wood as ornamentation was developed into a technique known as veneering.

In later centuries, as furniture making became a sophisticated art, veneering came into wide use. Furniture makers found that a veneer of beautifully grained walnut, for example, could increase the value of a piece made primarily of less-expensive wood.

Veneering also gave craftspeople the freedom to use ornate and attractive "flaws," such as burls or knots, which were unreliable for use as structural parts. Beautiful examples of European veneered furniture date from the 17 th and 18th centuries, along with fine examples of Chinese veneer. The technique gained even greater popularity in the 19 th century, when industrially processed plywood became common enough to be used in everyday furniture for the middle classes.

The development of "veneered wood," or plywood, as it is currently known, also follows the growth of the furniture industry. Plywood is a composite wood product made of thin layers of wood glued together and arranged so that the grain directions of adjoining layers are perpendicular to each other. This technique results in a wood slab with material strength equal in both directions. A balanced construction of plywood has an odd number of layers, consisting of an identical assembly on both sides of the center layer, or core. Such a balanced construction works well to minimize warping because the opposing grain directions tend to cancel changes in successive layers.

Plywood is frequently used when large areas must be covered with a light, rigid sheeting. The primary softwoods (defined as the wood from coniferous trees) used in plywood construction include Douglas-fir, hemlock, southern pine, and ponderosa pine; hardwood plywoods are made of oak, yellowpoplar, red gum, elm, birch, ash, cherry, and walnut. Layer thicknesses range from about $1 / 28$ inch to $1 / 8$ inch ( 1 to 3 $\mathrm{mm}$ ). Thin exterior veneers also make expensive decorative wood go farther. The most common finished plywoods range in thickness from three-ply ( $3 / 8$ inch or about $1 \mathrm{~cm}$ ) to five-ply $(3 / 4$ inch or $1.9 \mathrm{~cm}$ ), though other thicknesses are used for specific applications.

The appropriate layers are assembled and arranged in gluing presses, which use either natural adhesives (animal, soybean, starch, or casein) or synthetic resins (phenol- or urea-formaldehyde) to glue the plywood together. Some resins actually produce bonds stronger than the wood, resulting in resistance to interfacial attack by water, weather, steam, microorganisms, insects, and fungus.

In the 1860 s, U.S. patents were issued for the use of thin sheets of veneered wood, perforated and bent, to be made into chair seats and backs. At about the same time, a sandwich construction called "lumber-cored board" came into use-a core of thick, solid wood, faced with thin veneers. Lumber-cored board found wide application in tabletops and desktops.

During the late 1800 s and early 1900 s, the mass-production of poorly made furniture and the widespread use of inferior veneered wood as backings for inexpensive mirrors and chests, cheap chair seats, and drawer bottoms brought "veneered wood" into disrepute. In the 1910s, with much-improved manufacturing processes and tighter quality standards, manufacturers introduced the term "plywood" to differentiate their new wood product from its shoddy predecessors.

In addition to being stronger across the grain direction than natural wood, plywood has other advantages over solid natural wood: Because the grains of the layers cross each other, plywood exhibits almost no shrinking or swelling compared to hardwood. Plywood can be manufactured in large sheets that are broader than a tree. Plywood exhibits less splitting and splintering during nailing and cutting than does solid wood.
Also, plywood can be made with lower grade wood covered with higher grade surface veneers, which results in cost savings.

The thin sheets of veneer used for the individual layers dry rapidly, allowing the manufacture of plywood from relatively green lumber. Also, since wood is more easily cut and shaped when wet, but is stronger when dry, the wood can be cut and processed in steam, after which it quickly regains its strength.

Special types of plywood designed for bending or equal distribution of torsional stress can be layered with the grain directions in adjacent layers at angles of 30, 45, or $60^{\circ}$ in relation to each other. If the grain directions are aligned in parallel in succeeding layers, the product is called "laminated wood," most commonly recognized as "Bentwood" furniture. Another product, "plymetal," is a type of plywood with alternating layers of wood and metal sheets, designed for truck and railroad car bodies, where wear patterns require hard, dense layers.

Other processed-wood products have become popular during the past several decades, making efficient use of logging residues and waste wood. Particleboard, or chipboard, first developed in the 1940s, is made of dried chips, flakes, and shavings that are mixed with a resin adhesive, formed into mats, compressed, and assembled into boards. The particleboard binder also includes water repellents and mildew inhibitors. Particleboard is usually manufactured in three grades of density and at thicknesses between $1 / 5$ to 1 inch $(6-25 \mathrm{~mm})$. Some particleboard sheets are made in plywood-style layers, with mixtures of different major particle sizes and geometries.

Fiberboard, another alternative wood product, is made of wood fibers or other vegetable fibers mixed with binders and other additives, and felted or matted together into sheets. Low-density fiberboard is used for insulation; high-density sheets can be used for paneling.

Overall, "panel products" such as plywood, particleboard, and fiberboard are used in a wide variety of products. In building construction alone, these products are employed in walls and wall paneling, floors, roofs, doors, exterior siding, and shelves. Other uses include furniture, ships, railroad cars, and toys.

Wood has been used for thousands of years in countless ways. This natural substance is still used widely today, and remains the best material for many applications.

KEVIN J. ANDERSON 